\title{
Correction to: Pharmacological evaluation of prophylactic anti-microbial use in laparoscopic cholecystectomy; an open labelled study evaluating the concentrations of single dose intravenous ceftriaxone at serum and tissue level
}

\author{
Salim Sheikh ${ }^{1,2}$ - Neeraj Kumar Malik ${ }^{1} \cdot$ Chakra Dhar Tripathi $^{1,2}$. Satya Vrat Arya ${ }^{3}$. Veena Verma ${ }^{1}$. \\ Bushra Ahmed Karim ${ }^{4}$ (D) Girish Gulab Meshram ${ }^{1,2}$
}

Published online: 21 May 2021

(c) Springer-Verlag GmbH Germany, part of Springer Nature 2021

\section{Correction to: European Journal of Clinical Pharmacology https://doi.org/10.1007/s00228-021-03093-1}

The 1st, 3rd and 6th Author name is presented correctly in this paper.

The original article can be found online at https://doi.org/10.1007/ s00228-021-03093-1.

Bushra Ahmed Karim

bushrakarim786@gmail.com

Salim Sheikh

drsalimsheikh@gmail.com

1 Department of Pharmacology, Employees' State

Insurance Corporation Medical College and Hospital,

Faridabad 121001, India

2 Department of Pharmacology, Vardhman Mahavir Medical College and Safdarjung Hospital, New Delhi 110029, India

3 Department of Surgery, Vardhman Mahavir Medical College and Safdarjung Hospital, New Delhi 110029, India

4 Department of Public Health Dentistry, Faculty of Dentistry, Jamia Millia Islamia, New Delhi 110025, India 